\title{
Comparison of Cadmium Adsorption by Inorganic Adsorbents in Column Systems
}

\author{
E. Gutiérrez-Segura • M. Solache-Ríos • \\ A. Colín-Cruz • C. Fall
}

Received: 28 October 2013 / Accepted: 25 March 2014 / Published online: 11 May 2014

(C) Springer International Publishing Switzerland 2014

\begin{abstract}
Carbonaceous material obtained from industrial sewage sludge and Na-zeolitic tuff were used to adsorb cadmium from aqueous solutions in column systems. The Bohart, Thomas, Yoon-Nelson, and mass transfer models were successfully used to fit the adsorption data at different depths, and the constant rates were evaluated. The parameters such as breakthrough and saturation times, bed volumes, kinetic constants, adsorption capacities, and adsorbent usage rates (AUR) were determined. The results show that the breakthrough time increases proportionally with increasing bed height. The adsorption capacity for cadmium for Na-zeolitic tuff was higher than carbonaceous material. The results indicated that the Na-zeolitic tuff is a good adsorbent for cadmium removal.
\end{abstract}

Keywords Adsorption - Cadmium - Zeolitic tuff . Sewage sludge $\cdot$ Carbonaceous material

E. Gutiérrez-Segura • A. Colín-Cruz

Facultad de Química, Universidad Autónoma del Estado de México, Paseo Colón y Tollocan s/n, 50000 Toluca, Estado de México, Mexico

\section{Solache-Ríos $(\bowtie)$}

Departamento de Química, Instituto Nacional de Investigaciones Nucleares, A. P. 18-1027, Col. Escandón, Delegación Miguel Hidalgo, 11801 Mexico, D. F., Mexico e-mail: marcos.solache@inin.gob.mx

C. Fall

Centro Interamericano de Recursos del Agua, CIRA, km 14.5 de la Carretera Toluca, Unidad San Cayetano, Ixtlahuaca, Estado de México, Mexico

\section{Introduction}

Environmental pollution by heavy metals is a serious and complex problem that it is a focus of attention worldwide. Metals such as lead, cadmium, copper, nickel, chromium, zinc, and mercury have been recognized as hazardous heavy metals. Unlike organic wastes, heavy metals are nonbiodegradable and they react with the body's biomolecules to form extremely stable biotoxic compounds which are difficult to dissociate causing various diseases and disorders (Hashim et al. 2011; Ahmaruzzaman et al. 2011).

Cadmium is one of the few elements that seems to have no function in human or animal life. Cadmium exposure can provoke cancer, kidney damage, mucous membrane destruction, vomiting, diarrhea, bone damage, and itai-itai disease, as well as affects the production of progesterone and testosterone and leads to lung disease (Lesmana et al. 2009; Wang and Lin 2010; Fu and Wang 2011).

The Word Health Organization (World Health Organization 2008) has announced a maximum cadmium uptake of $0.003 \mathrm{mg} / \mathrm{L}$ in drinking water; its toxicity is known in all its forms (metal, vapor, salts, and inorganic and organic compounds).

There are many treatment processes to remove metal ions from aqueous solution, such as chemical precipitation, filtration, evaporation, ion exchange, electrochemical treatment, membrane technologies, adsorption on activated carbon, etc. Chemical precipitation and electrochemical treatment are ineffective, especially when metal ion concentration in aqueous solution is from 1 to $100 \mathrm{mg} / \mathrm{L}$ and also produce large quantities of sludges. 
Ion exchange, membrane technologies, and activated carbon adsorption process are extremely expensive when treating a large amount of water and wastewater containing heavy metals in low concentrations; they cannot be used at large scale (Ahmaruzzaman 2011; Bulut and Tez 2007). Table 1 summarizes the advantages and disadvantages of those conventional metal removal technologies.

Adsorption has acquired global importance to minimize the contamination problem of water and air, and this process has become a significant addition to green chemistry endeavors (Bhattacharyya and Gupta 2008; Lesmana et al. 2009). Adsorption has additional advantages; for example, it may be applicable to solutions of low concentrations, suitable for using batch and continuous processes, ease of operation, little sludge generation, and possible regeneration and reuse. However, the high price of adsorbents (usually activated carbon) is regarded as the major obstacle for industrial applications (Lesmana et al. 2009).

Natural materials, wastes/by-products of industries, or synthetically prepared materials that require some minor treatment can be used as alternative adsorbents (Fu and Wang 2011). Some low-cost adsorbents for the removal of heavy metals include: zeolites (GutiérrezSegura et al. 2012; Cortés-Martínez et al. 2009), carbonaceous material from sewage sludge (Gutiérrez-Segura et al. 2009), polymer modified $\mathrm{Fe}_{3} \mathrm{O}_{4}$ nanoparticles
(Badruddoza et al. 2013), dead plant biomass (Saraswat and Rai 2010), mesoporous silica, and activated carbon (Machida et al. 2012).

Sewage sludge formed during sewage treatment constitutes a serious economic problem. The common disposal processes for sewage sludges include land filling, agricultural application, and incineration (Fonts et al. 2012). Although there are several sewage sludge disposal methods, it is better to make use of these waste materials by turning them into a resource. The pyrolysis of sewage sludge is an alternative to conventional combustion process; it consists in the thermal decomposition of organic substances under oxygendeficient circumstances, where the volume of the solid is drastically reduced to obtain a carbonaceous material and the heavy metals present in the carbonaceous matrix are relatively resistant to natural lixiviation (Pokorna et al. 2009). The means of production, the characteristics and potential application of sewage sludge-based adsorbents obtained by pyrolysis, and other methods of carbonization have been reviewed in detail by Fytili and Zabaniotou (2008) and Smith et al. (2009).

Removal of cadmium using carbonaceous material from pyrolyzed sewage sludge (Gutiérrez-Segura et al. 2012) and natural zeolites has been evaluated (Hamidpour et al. 2010; Jamil et al. 2010; Teutli-Sequeira et al. 2009; Ji et al. 2012) in adsorption equilibrium; however, these processes have not been reported in continuous systems.

Table 1 Current treatment technologies for heavy metal removal involving physical and/or chemical processes (Ahmaruzzaman 2011)

\begin{tabular}{|c|c|c|}
\hline $\begin{array}{l}\text { Physical and/or chemical } \\
\text { methods }\end{array}$ & Advantages & Disadvantages \\
\hline Ion exchange & Efficient removal & Adsorbents require regeneration or disposal \\
\hline $\begin{array}{l}\text { Membrane filtration } \\
\text { technologies }\end{array}$ & Efficient removal & $\begin{array}{l}\text { Concentrated sludge production and expensive } \\
\text { treatment }\end{array}$ \\
\hline Adsorption by activated carbon & $\begin{array}{l}\text { Flexibility and simplicity of design, ease operation, } \\
\text { and insensitivity to toxic pollutants }\end{array}$ & High price of adsorbents and requires regeneration \\
\hline Coagulation/flocculation & Economically feasible & $\begin{array}{l}\text { High sludge production and formation of large } \\
\text { particles }\end{array}$ \\
\hline Electrochemical treatment & Rapid process and effective for certain metal ions & High energy costs and formation of by-products \\
\hline Ozonation & Applied in gaseous state: alteration of volume & Short half-life \\
\hline Photochemical & No sludge production & Formation of by-products \\
\hline Irradiation & Effective at lab scale & Required a lot of dissolved $\mathrm{O}_{2}$ \\
\hline Electrokinetic coagulation & Economically feasible & High sludge production \\
\hline Fenton's reagents & $\begin{array}{l}\text { Effective and capable of treating a variety of } \\
\text { wastes and no energy input necessary to } \\
\text { active hydrogen peroxide }\end{array}$ & Sludge generation \\
\hline Biological treatment & Feasible in removing some metals & Technology yet to be established and commercialized \\
\hline
\end{tabular}


Equilibrium adsorption is useful to determine the adsorption mechanisms, the adsorption kinetic behaviors, and the adsorption capacities. However, industrial adsorption processes are usually performed in fixed-bed column systems which do not reach the sorption equilibrium (Cooney 1998).

The purpose of the present work was to compare and determine the adsorption behavior of cadmium using a Na-zeolitic rock and a carbonaceous material in continuous systems and to determine the basic parameters that could be useful to design a column system for cadmium wastewater treatment.

\section{Materials and Methods}

The clinoptilolite-rich tuff from Villa de Reyes, San Luis Potosi, Mexico, was milled and sieved. The grain size used was between 0.8 and $1.0 \mathrm{~mm}$. The zeolitic material was treated with a solution of sodium chloride and refluxed $(50 \mathrm{~g}$ of material with $250 \mathrm{~mL}$ of a $0.125-\mathrm{M}$ $\mathrm{NaCl}$ solution); this procedure was repeated four times. The zeolitic material was washed with distilled water until no presence of chloride ions was indicated in the washing solution using a $\mathrm{AgNO}_{3}$ test; then, the sodiumtreated zeolitic tuff (Na-Z) was dried at $60^{\circ} \mathrm{C}$ for $2 \mathrm{~h}$.

The carbonaceous material was obtained from industrial sewage sludge. The sludge feedstock and the pyrolysis procedure have been described elsewhere (Torres Pérez et al. 2008). The pyrolysis of the sludge was performed at $500{ }^{\circ} \mathrm{C}$ for $60 \mathrm{~min}$. Later, the samples were milled and sieved, and grains with diameters between 0.42 and $0.84 \mathrm{~mm}$ were selected. The carbonaceous material was then treated with $10 \%$ hydrochloric acid solution at $20{ }^{\circ} \mathrm{C}$ for $8 \mathrm{~h}$. It was washed five times with distilled water and dried at $100{ }^{\circ} \mathrm{C}$ for $2 \mathrm{~h}$. A full characterization of these materials has been reported elsewhere (Gutiérrez-Segura et al. 2012). Stock cadmium solutions (100 and $300 \mathrm{mg} / \mathrm{L}$ ) were prepared with deionized water using $\mathrm{Cd}\left(\mathrm{NO}_{3}\right)_{2} \cdot 4 \mathrm{H}_{2} \mathrm{O}$ (analytical grade).

\subsection{Fixed-Bed Experiments}

The adsorption process was conducted in 4, 8, and 16-cm bed high in glass columns of $1.0 \mathrm{~cm}$ internal diameter. The weights of adsorbents were 2.1, 4.9, and $10.0 \mathrm{~g}$ of Na-zeolitic tuff and 1.6, 3.4, and $6.8 \mathrm{~g}$ of carbonaceous material; the fixed-bed volumes for both adsorbents were
$3.14,6.28$, and $12.56 \mathrm{~cm}^{3}$. Glass wool was put in the bottom of the column to support the adsorbent.

The columns were fed with solutions of $60 \mathrm{mg} / \mathrm{L}$ of cadmium at a constant volumetric flow rate of $5 \mathrm{~mL} / \mathrm{min}$ and $\mathrm{pH}$ of 6.0 in downflow mode. This volumetric flow rate was calculated according to Tchobanoglous et al. (2003). Liquid samples were withdrawn at different time intervals until the effluent concentration was equal to the influent concentration. Cadmium concentrations were determined in the liquid phases at $\lambda=228.8 \mathrm{~nm}$ by atomic absorption spectroscopy (GBC-932 plus). The breakthrough curves were obtained by plotting $C_{\mathrm{e}} / C_{0}$ (effluent concentration/influent concentration) of cadmium vs. time. The breakthrough time $\left(t_{\mathrm{b}}\right)$ chosen in this study was the time where cadmium concentration in the effluent reached $1 \mathrm{mg} / \mathrm{L}$; the bed exhaustion or saturation time $\left(t_{\mathrm{s}}\right)$ was chosen to be the time where cadmium concentration in the effluent reached $99 \%$ of the initial cadmium concentration.

\subsection{Mathematical Models}

Experimental evaluation of the performance of a fixed-bed column is generally possible at laboratory scale. The data collected during laboratory studies can be utilized to predict and evaluate the performance of higher size columns by applying suitable mathematical models developed for such purposes (Hasan et al. 2010). The experimental data were fitted to the mathematical models by using the program Origin Pro 8.0.

The removal of cadmium from aqueous solution onto Na-zeolitic tuff and carbonaceous material in a fixed bed was expressed in terms of $C_{\mathrm{e}} / C_{0}$ (where $C_{0}$ and $C_{\mathrm{e}}$ are the influent and effluent cadmium concentration, respectively) as a function of either volume of effluent or time. The treated effluent volume, $V_{\mathrm{s}}$, is calculated using Eq. 1:

$V_{\mathrm{s}}=Q t_{\mathrm{s}}$

where $Q$ is the volumetric flow rate $(\mathrm{L} / \mathrm{min})$ and $t_{\mathrm{s}}$ is the time at saturation (min). The total amount of cadmium in the column, $m_{\text {total }}$, is computed by using Eq. 2:

$m_{\text {total }}=C_{0} Q t_{\mathrm{s}}$

The uptake capacity at breakthrough point $\left(q_{\mathrm{b}}\right)$ or the amount of cadmium adsorbed per unit dry weight of 
adsorbent at breakthrough $(\mathrm{mg} / \mathrm{g})$ is given by the Eq. 3 (Tchobanoglous et al. 2003):

$q_{\mathrm{b}}=\int_{0}^{V_{\mathrm{b}}} \frac{\left(C_{0}-C_{\mathrm{b}}\right) d V}{M}$

where $M$ is the mass of adsorbent $(\mathrm{g})$ and $V_{\mathrm{b}}$ is the volume of solution passed until breakthrough point $(\mathrm{mL})$. Similarly, the uptake capacity of adsorbent at saturation time $\left(q_{\mathrm{b}}\right.$ in $\left.\mathrm{mg} / \mathrm{g}\right)$ is calculated from Eq. 4 :

$q_{\mathrm{b}}=\int_{0}^{V_{\mathrm{s}}} \frac{\left(C_{0}-C_{\mathrm{s}}\right) d V}{M}$

where $V_{\mathrm{s}}$ is the volume of cadmium solution to reach saturation (L).

The percentage of cadmium removed by the column is the ratio of the total cadmium retained by the column divided by the total amount of cadmium input to the column, which is given by Eq. 5 :

Metal removal $(\%)=\frac{m_{\mathrm{ad}}}{m_{\text {total }}} 100$

where $m_{\mathrm{ad}}$ is the total metal retained by the column (g), which is the area found above the breakthrough curve and is obtained by numerical integration.

The steepness $(\mathrm{dc} / \mathrm{dt})$ of breakthrough curve is a measure of the efficiency of column to reach the saturation and is obtained from $t_{\mathrm{b}}$ (time at breakthrough point) to $t_{\mathrm{s}}(\mathrm{min})$.

The mass transfer zone $\left(Z_{\mathrm{m}}\right)$ represents the length of bed over which the concentration in the fluid phase changes from an upper value $C_{1}$ (breakthrough time) to a lower value $C_{2}$ (saturation time); the length of this zone is an index of the rate of mass transfer (Cooney 1998), and it is computed using Eq. 6:

$Z_{\mathrm{m}}=Z\left(1-\frac{t_{\mathrm{b}}}{t_{\mathrm{s}}}\right)$

where $Z_{\mathrm{m}}$ is the length of the mass transfer zone $(\mathrm{cm}), Z$ is the bed depth $(\mathrm{cm}), t_{\mathrm{b}}$ is the time at breakthrough (min), and $t_{\mathrm{s}}$ is the time at saturation (min) (Futalan et al. 2011; Singh et al. 2012).

Another useful parameter suggested to evaluate the performance of adsorbent materials as a function of the working conditions, and the amount and nature of the pollutant is the adsorbent usage rate; this is a parameter of practical significance and is equal to the adsorbent weight in the column (g) divided by the amount of liquid eluted in the column up to the breakthrough region (L) and is expressed as follows (Cooney 1998; Pastrana-Martínez et al. 2010):

Adsorbent usage rate $($ AUR $)=\frac{\text { Adsorbent inside the column }}{\text { Volume treated at breakthrough }}$

\subsection{Bohart-Adams Model}

The expression of the model is the following (GutiérrezSegura et al. 2012):

$\frac{C_{\mathrm{e}}}{C_{\mathrm{o}}}=\exp \left(k_{\mathrm{BA}} C_{\mathrm{o}} t-k_{\mathrm{BA}} N_{\mathrm{o}} \frac{Z}{U}\right)$

where $k_{\mathrm{BA}}$ is the kinetic constant ( $\left.\mathrm{L} / \mathrm{mg} \min \right), U$ is the linear flow rate $(\mathrm{cm} / \mathrm{min}), Z$ is the bed depth of column $(\mathrm{cm})$, and $N_{\mathrm{o}}$ is adsorption capacity $(\mathrm{mg} / \mathrm{L})$. The $k_{\mathrm{BA}}$ and $N_{\mathrm{o}}$ values that describe the characteristic operational parameters of the column can be calculated using nonlinear regression analysis.

Huchins (Cortés-Martínez et al. 2009) presented a modification of Bohart-Adams equation which is called "bed depth service time" (BDST) approach and is expressed as:

$t=\frac{N_{\mathrm{o}} Z}{C_{\mathrm{o}} U}-\frac{1}{k_{\mathrm{BA}} C_{0}} \ln \left(\frac{C_{0}}{C_{\mathrm{b}}}-1\right)$

where $t$ is the service time at breakthrough, $U$ is the linear flow rate $(\mathrm{cm} / \mathrm{min}), Z$ is the bed depth $(\mathrm{cm}), k_{\mathrm{BA}}$ is the Bohart-Adams constant $(\mathrm{L} / \mathrm{mg} \mathrm{min})$, $N_{\mathrm{o}}$ is the adsorption capacity of the adsorbent $(\mathrm{mg} / \mathrm{L})$, $C_{0}$ is influent concentration $(\mathrm{mg} / \mathrm{L})$, and $C_{\mathrm{b}}$ is concentration at breakthrough $(\mathrm{mg} / \mathrm{L})$, respectively. Equation (10) has the form of a straight line:

$t_{\mathrm{b}}=m Z+b$

\subsection{Thomas Model}

The equation of the model is as follows:

$\frac{C}{C_{\mathrm{o}}}=\frac{1}{1+\exp \left(K_{\mathrm{Th}} q_{\mathrm{o}} m / Q-K_{\mathrm{Th}} C_{\mathrm{o}} t\right)}$

where, $K_{\mathrm{Th}}$ is the Thomas rate constant ( $\left.\mathrm{L} / \mathrm{min} \mathrm{mg}\right), q_{\mathrm{o}}$ is the sorption capacity of adsorbent $(\mathrm{mg} / \mathrm{g}), Q$ is the 
volumetric flow rate $(\mathrm{L} / \mathrm{min})$, and $m$ is the mass of the adsorbent (g).

\subsection{Yoon-Nelson Model}

The Yoon and Nelson equation regarding to a single component system is expressed as the following:

$\frac{C}{C_{\mathrm{o}}}=\frac{\exp \left(K_{\mathrm{YN}} t-\tau K_{\mathrm{YN}}\right)}{1+\exp \left(K_{\mathrm{YN}} t-\tau K_{\mathrm{YN}}\right)}$

where $K_{\mathrm{YN}}$ is the rate constant $\left(\mathrm{min}^{-1}\right)$; $\tau$, the time required for $50 \%$ adsorbate breakthrough ( $\mathrm{min}$ ). Due to the symmetrical nature of the breakthrough curve, the amounts of cadmium adsorbed by the adsorbents are one half of the total cadmium entering the sorption column within the $2 \tau$ period. Hence, the following Eq. 13 can be written (Köse and Öztürk 2008):

$q_{\mathrm{o}}=\frac{1}{2} \frac{C_{\mathrm{o}} Q(2 \tau)}{m}=\frac{C_{\mathrm{o}} Q \tau}{m}$

This equation also permits the determination of the adsorption capacity of the column $\left(q_{\mathrm{o}}\right)$ as a function of initial metal concentration $\left(C_{\mathrm{o}}\right)$, flow rate $(Q)$, mass quantity in the column $(\mathrm{m})$, and $50 \%$ breakthrough time $(\tau)$.

\subsection{Mass Transfer Model}

The mass transfer rate is a combination of local mass transfer through the external film (mass transfer coefficient, $k$ ) and intraparticle diffusion (diffusion coefficient, $D$ ), through macro and/or micropores. The diffusion is normally assumed to be driven by the concentration gradient (Won et al. 2012). This model was used successfully by Barros et al. (2004) in the removal of chromium in fixed-bed columns using zeolite $\mathrm{NaX}$ as sorbent. The model considers the following:

- One dimensional flow and diffusion in the axial direction

- The fluid temperature, density, and velocity are constant.

- Mass diffusivity is independent of the concentration of the solute.

- No intraparticle diffusion

The data obtained from the batch adsorption isotherm can be used to predict the theoretical breakthrough curve, which can be compared with the experimental curve. The Langmuir model was considered because the experimental data were best fitted to the Freundlich model (Gutiérrez-Segura et al. 2012). The differential mass balance equation for a fixed-bed column is given by the following:

$\frac{\partial C}{\partial t}=-v \frac{\partial C}{\partial x}+D \frac{\partial x^{2} C}{\partial x^{2}}-D_{0} \frac{\partial q}{\partial t}$

where $C$ is the fluid phase metal concentration, $q$ is the metal concentration in the sorbent averaged over the sorbent volume, $v$ is the interstitial velocity, $D$ is the diffusion coefficient, $x$ is the axial distance in the column, and $t$ represents time (Muhamad, et al. 2010). The mass transfer model (Eq. (14)) was solved by using AQUASIM software.

The parameter $K$ was determined by Langmuir isotherm model, by assuming $b=1 / K$, described by the following form:

$q_{\mathrm{eq}}=\frac{q_{\mathrm{max}} b C}{1+b C}$

\section{Results and Discussion}

Successful design of a column sorption process required prediction of the behavior of the concentration of the effluent in a determined time or breakthrough curve. In this work, the effect on the shape of the breakthrough curves, breakthrough times, and column performances were investigated.

Figures 1 and 2 show the breakthrough curves obtained for cadmium sorption onto Na-zeolitic tuff and carbonaceous material, respectively, at different bed depths. The breakthrough curves become sharper as the bed depth increases from 4 to $16 \mathrm{~cm}$. The Mexican regulations establish tolerance limits to discharge cadmium in wastewater of $1 \mathrm{mg} / \mathrm{L}$ (NOM-002SEMARNAT 1996), and therefore, this value was taken in this work as the breakpoint and saturation points were taken at $99 \%$ of the influent concentration.

As shown in Table 2, the time required for attaining the breakthrough or saturation increased with increasing bed depth for both adsorbents. Similarly, bed volume at breakthrough or saturation increased with increasing bed depth. The $Z_{\mathrm{m}}$ increased from 3.97 to 11.67 and 3.94 to $14.9 \mathrm{~cm}$ as the bed depth increases for Na-zeolitic tuff and carbonaceous material, respectively. This displacement of 
Fig. 1 Breakthrough curves of cadmium by Na-zeolitic tuff in columns of different bed depth and adjustments to the Bohart-Adams, Thomas, and Yoon-Nelson models

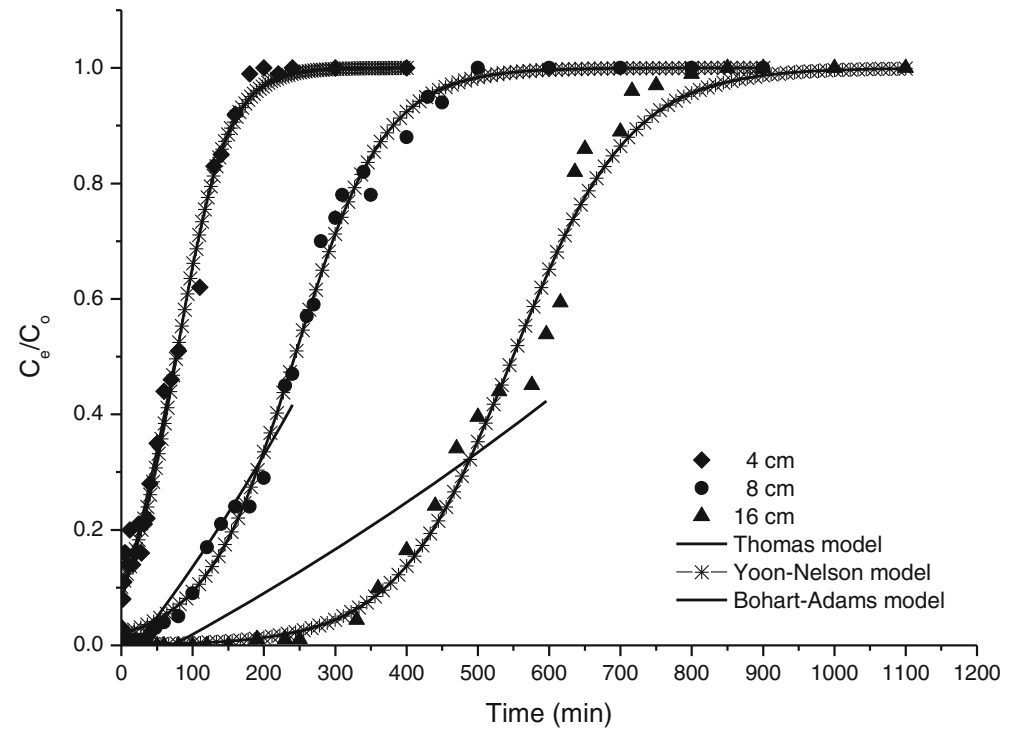

the front of adsorption with increasing the depth of beds can be explained by mass transfer phenomena that take place in this process. When the bed depth was reduced, axial dispersion phenomena increased in the mass transfer and reduce the diffusion of metallic ions. Jain et al. (2013) studied the cadmium sorption by sunflower waste carbon calcium-alginate in a fixed-bed system and reported an increase in breakthrough time with increasing bed depth.

The cadmium maximum adsorption capacities were obtained at a $16-\mathrm{cm}$ bed depth. The adsorption capacities were estimated to be 6.19 and $1.54 \mathrm{mg} / \mathrm{g}$ for Na-zeolitic tuff and carbonaceous material, respectively, and the corresponding metal removal efficiency was not affected (98\%). The adsorption capacity for cadmium increases with increasing bed depth by having sufficient time for the adsorbate to diffuse into the whole mass of the adsorbent and an increase of the surface area of adsorbent mass that provides more binding sites for adsorption in a column with a longer bed depth. Columns with short bed depth saturate quickly due to lesser availability of sorbent and hence metal-binding sites (Zulfadhly et al. 2001).
Fig. 2 Breakthrough curves of cadmium by carbonaceous material in columns of different bed depth and adjustments to the Bohart-Adams, Thomas, and Yoon-Nelson models

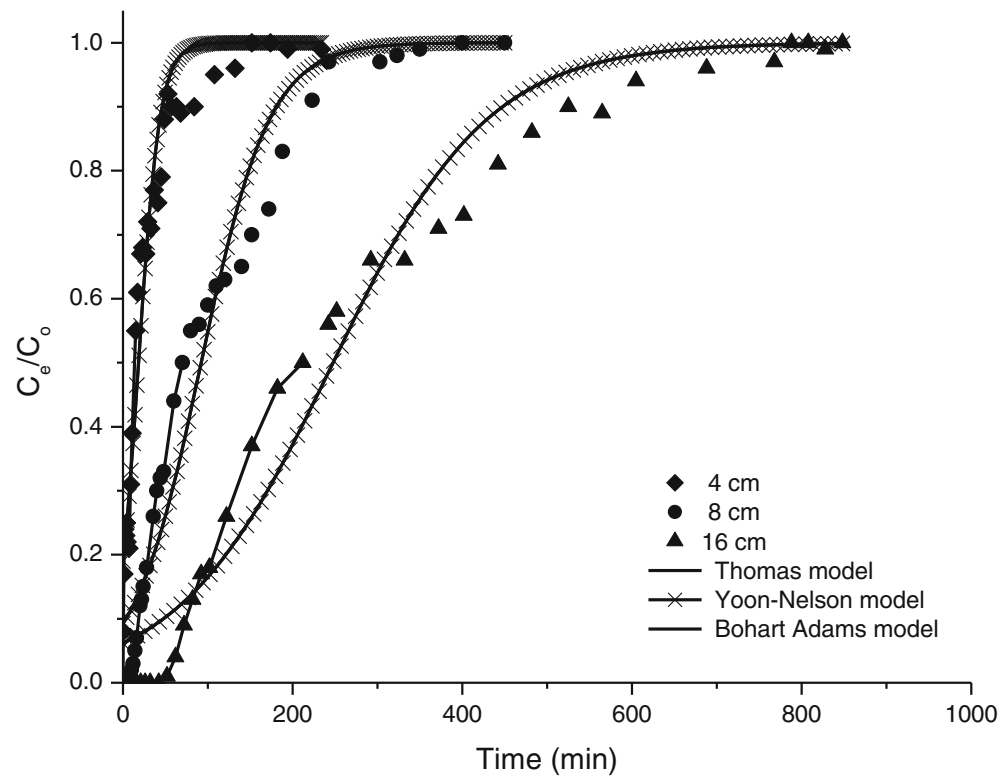


Table 2 Adsorption data of cadmium removal using Na-zeolitic tuff (Na-Z) and carbonaceous material (MC) in a fixed-bed system at different bed depths

\begin{tabular}{|c|c|c|c|c|c|c|c|c|}
\hline \multirow[t]{2}{*}{ Bed depth $(\mathrm{cm})$} & \multicolumn{7}{|c|}{ Experimental parameters of breakthrough curve } & \multirow[t]{2}{*}{$\mathrm{dc} / \mathrm{dt}(\mathrm{mg} / \mathrm{L} \mathrm{min}) \times 10^{-3}$} \\
\hline & $t_{\mathrm{b}}(\min )$ & $t_{\mathrm{s}}(\min )$ & $\mathrm{BV}_{\mathrm{b}}$ & $\mathrm{BV}_{\mathrm{s}}$ & $Z_{\mathrm{m}}(\mathrm{cm})$ & $q_{\mathrm{b}}(\mathrm{mg} / \mathrm{g})$ & $\mathrm{MR}_{\mathrm{b}}(\%)$ & \\
\hline $\mathrm{ZNa} 4$ & 1 & 180 & 1.6 & 288 & 3.97 & 0.12 & 98.3 & 17 \\
\hline $\mathrm{ZNa} 8$ & 40 & 400 & 32 & 320 & 7.20 & 2.45 & 98.4 & 8.6 \\
\hline $\mathrm{ZNa} 16$ & 230 & 850 & 92 & 340 & 11.67 & 6.19 & 98.2 & 4.3 \\
\hline MC 4 & 1 & 71 & 1.6 & 113.6 & 3.94 & 0.17 & 98.3 & 45 \\
\hline $\mathrm{MC} 8 \mathrm{~cm}$ & 9 & 350 & 7.2 & 280 & 7.79 & 0.83 & 98.4 & 9.4 \\
\hline $\mathrm{MC} 16 \mathrm{~cm}$ & 52 & 760 & 20.8 & 304 & 14.90 & 1.54 & 98.3 & 4.2 \\
\hline
\end{tabular}

$t_{b}$ breakthrough time ( $\left.\mathrm{min}\right), t_{s}$ saturation time ( $\left.\mathrm{min}\right), B V_{b}$ bed volumes at breakthrough, $B V_{s}$ bed volumes at saturation, $Z_{m}$ length of the mass transfer zone $(\mathrm{cm}), q_{b}$ adsorption at breakthrough $(\mathrm{mg} / \mathrm{g}), \% M R_{b}$ metal removal at breakthrough, $d c / d t$ slope of the breakthrough curve $(\mathrm{mg} / \mathrm{L} \mathrm{min})$

These results are smaller than those obtained in equilibrium systems because the time required to reach the equilibrium between adsorbent and heavy metal solutions is much longer (about $7 \mathrm{~h}$ for Na-zeolitic tuff and $48 \mathrm{~h}$ for carbonaceous material) (GutiérrezSegura et al. 2012), and the data reflect the affinity of the adsorbent material for the heavy metal which it is higher for Na-zeolitic tuff than carbonaceous material.

The steepness of breakthrough curves for cadmium adsorption for both adsorbents decreased with increasing depth; this behavior results in a broadened mass transfer zone, which makes breakthrough curves less steeper. The shape of the curves indicates that it is more difficult to saturate the beds as their depths increase; similar behaviors were observed elsewhere (Lodeiro et al. 2006; Naja and Volesky 2008; Chen et al. 2011).

The results shown in Table 3 indicate that $1 \mathrm{~L}$ of cadmium solution of $60 \mathrm{mg} / \mathrm{L}$ can be treated with $8 \mathrm{~g}$ of Na-zeolitic tuff or $33 \mathrm{~g}$ of carbonaceous material. The relation between AUR and bed depth indicates that the AUR decreased significantly from 4 to 8 -cm bed depth for Na-Zeolitic tuff, and this decrement is lower for carbonaceous material. Similarly, Girgis et al. (2008) studied the removal of palladium complexes using

Table 3 AUR for removal of cadmium from $1 \mathrm{~L}$ of an aqueous solution of $60 \mathrm{mg} / \mathrm{L}$

\begin{tabular}{lll}
\hline $\mathrm{Z}(\mathrm{cm})$ & Na-Z use $(\mathrm{g} / \mathrm{L})$ & CM use $(\mathrm{g} / \mathrm{L})$ \\
\hline 4 & 518 & 357 \\
8 & 24 & 75 \\
16 & 8 & 33 \\
\hline
\end{tabular}

a fixed-bed adsorption system, and their results showed that the adsorption efficiency of palladium was not improved significantly by increasing the bed residence time.

The adsorption data from column elutions were analyzed by using the Bohart-Adams, Thomas, Yoon-Nelson, and mass transfer models. BohartAdams model was applied to the sorption kinetics data until breakpoint was reached, and Thomas and Yoon-Nelson models were applied until saturation was reached.

\subsection{Bohart-Adams Model}

Breakthrough curves generally permit a description of the adsorption process since a breakthrough capacity is characteristic of a column under given experimental conditions (Han et al. 2009). The Bohart-Adams model is used to describe the initial part of a breakthrough curve (effluent concentration $\left(C_{\mathrm{e}}\right)<0.5$ influent concentration $\left(C_{\mathrm{o}}\right)$ ).

Figures 1 and 2 show the adjustments of the experimental results to the Bohart-Adams model, and Tables 4 and 5 summarize the $k_{\mathrm{BA}}, N_{\mathrm{o}}$, and $R^{2}$ parameters for Na-zeolitic tuff and carbonaceous material, respectively. The values of $N_{\mathrm{o}}$ increased while the values of $k_{\mathrm{BA}}$ decreased as column-bed depth increased for both adsorbents. This behavior could be attributed to the contact time of the cadmium solution with the adsorbent; as the column-bed depth increased, the contact time of cadmium solution with the adsorbent increases (the mass transfer zone increases) and then, 
Table 4 Parameters obtained from the breakthrough curves and adjustments to the Bohart-Adams, Thomas, Yoon-Nelson, and models for cadmium onto Na-zeolitic tuff at different bed depths

\begin{tabular}{|c|c|c|c|c|c|c|c|c|c|c|}
\hline \multicolumn{4}{|c|}{ Bohart-Adams model } & \multicolumn{3}{|c|}{ Thomas model } & \multicolumn{4}{|c|}{ Yoon-Nelson model } \\
\hline$Z(\mathrm{~cm})$ & $N_{\mathrm{o}}(\mathrm{mg} / \mathrm{L})$ & $\begin{array}{l}k_{\mathrm{BA}} \times 10^{-5} \\
(\mathrm{~L} / \mathrm{mg} \min )\end{array}$ & $R^{2}$ & $q_{\mathrm{o}}(\mathrm{mg} / \mathrm{g})$ & $\begin{array}{l}K_{\mathrm{Th}} \times 10^{-4} \\
(\mathrm{~L} / \mathrm{mg} \mathrm{min})\end{array}$ & $R^{2}$ & $q_{\mathrm{o}}(\mathrm{mg} / \mathrm{g})$ & $K_{\mathrm{YN}}(\mathrm{L} / \mathrm{min})$ & $\tau(\min )$ & $R^{2}$ \\
\hline 4 & 20706.30 & 7.28 & 0.9178 & 9.46 & 4.44 & 0.9878 & 9.46 & 0.02 & 77.28 & 0.9878 \\
\hline 8 & 29173.20 & 2.88 & 0.9507 & 13.04 & 2.98 & 0.9951 & 15.12 & 0.01 & 243.02 & 0.9950 \\
\hline 16 & 39780.41 & 1.07 & 0.8431 & 16.71 & 2.04 & 0.9887 & 15.07 & 0.01 & 549.27 & 0.9887 \\
\hline
\end{tabular}

the adsorption capacities increased and the kinetic constants $\left(k_{\mathrm{BA}}\right)$ decreased; a similar behavior was observed with the Thomas model, as shown below. The best results were found for the columns with the highest bed volume (BV) for both adsorbents, and it was found that the adsorption capacities $\left(N_{\mathrm{o}}\right)$ of Na-zeolitic tuff for cadmium were 5.1, 3.8, and 3.3 times higher than the capacity found for carbonaceous material for column depth of 4,8 , and $16 \mathrm{~cm}$, respectively. The values of the Bohart-Adams model parameters can be extrapolated to other influent concentrations and hydraulic loading rate (Goel et al. 2005). Although the BohartAdams model provides a simple and comprehensive approach to evaluate the adsorption column process, its validity is limited to the range of conditions used in the column (Han et al. 2009).

Figure 3 shows $t_{\mathrm{b}}$ and $t_{\mathrm{s}}$ vs. bed depth for Na-zeolitic tuff and carbonaceous material. The relationships obtained for cadmium sorption are as follows:

$(\mathrm{Na}-\mathrm{Z}) t_{\mathrm{b}}=19.75 Z-94$

$(\mathrm{MC}) t_{\mathrm{b}}=4.41 Z-20.5$

Breakthrough time is therefore the determining parameter of the process; the relation between bed depths vs. breakthrough time represents a linear function that can be extrapolated to superior bed depths of columns and can be useful to scale up the process for other bed depths without additional experimental runs (Kumar and Bandyopadhyay 2006). Furthermore, service time at breakthrough points is proportional to bed depth of column, as it is showed in Fig. 3. According to Eqs. 16 and 17 , the sorption capacity of Na-zeolitic tuff for cadmium is 4.5 times higher than that for carbonaceous material under the same experimental conditions. The critical bed depth $\left(Z_{0}\right)$ is the minimum bed depth necessary to produce an effluent concentration $C_{\mathrm{b}}$. By letting $t=0, Z_{0}$ is obtained from Eqs. 16 and 17 (Tian et al. 2013). The critical bed depth values for Na-zeolitic tuff and carbonaceous material were 4.64 and $4.75 \mathrm{~cm}$, respectively. These values were obtained from Eqs. 16 and 17 as the point where the best-fit line through the data intersects the abscissa. The critical bed depth depends on the kinetics of the adsorption process, on the amount of time available for adsorption to occur (i.e., the "residence" time of the fluid in the bed), on the adsorption capacity of the solid for the solute, and on the solute concentration corresponding to breakthrough $\left(C_{\mathrm{b}}\right)$ (Cooney 1998).

Similar values of critical bed depth were obtained for removal of $\mathrm{Hg}$ (II) using granulated activated carbon and activated carbon cloth, 4.9 and $2.8 \mathrm{~cm}$, respectively (Goyal, et al. 2009).

Table 5 Parameters obtained from the breakthrough curves and adjustments to the Bohart-Adams, Thomas, Yoon-Nelson, and models for cadmium onto carbonaceous material at different bed depths

\begin{tabular}{|c|c|c|c|c|c|c|c|c|c|c|}
\hline \multicolumn{4}{|c|}{ Bohart-Adams model } & \multicolumn{3}{|c|}{ Thomas model } & \multicolumn{4}{|c|}{ Yoon-Nelson model } \\
\hline$Z(\mathrm{~cm})$ & $N_{\mathrm{o}}(\mathrm{mg} / \mathrm{L})$ & $\begin{array}{l}k_{\mathrm{BA}} \times 10^{-4} \\
(\mathrm{~L} / \mathrm{mg} \min )\end{array}$ & $R^{2}$ & $q_{\mathrm{o}}(\mathrm{mg} / \mathrm{g})$ & $\begin{array}{l}K_{\mathrm{Th}} \times 10^{-4} \\
(\mathrm{~L} / \mathrm{mg} \mathrm{min})\end{array}$ & $R^{2}$ & $q_{\mathrm{o}}(\mathrm{mg} / \mathrm{g})$ & $K_{\mathrm{YN}}(\mathrm{L} / \mathrm{min})$ & $\tau(\min )$ & $R^{2}$ \\
\hline 4 & 4002.08 & 3.62 & 0.8158 & 3.26 & 12.40 & 0.9464 & 3.25 & 0.08 & 18.33 & 0.9464 \\
\hline 8 & 7623.66 & 1.08 & 0.9842 & 7.64 & 4.33 & 0.9516 & 7.64 & 0.02 & 92.17 & 0.9516 \\
\hline 16 & 12001.81 & 0.35 & 0.9577 & 10.38 & 1.86 & 0.9686 & 10.38 & 0.01 & 247.45 & 0.9686 \\
\hline
\end{tabular}



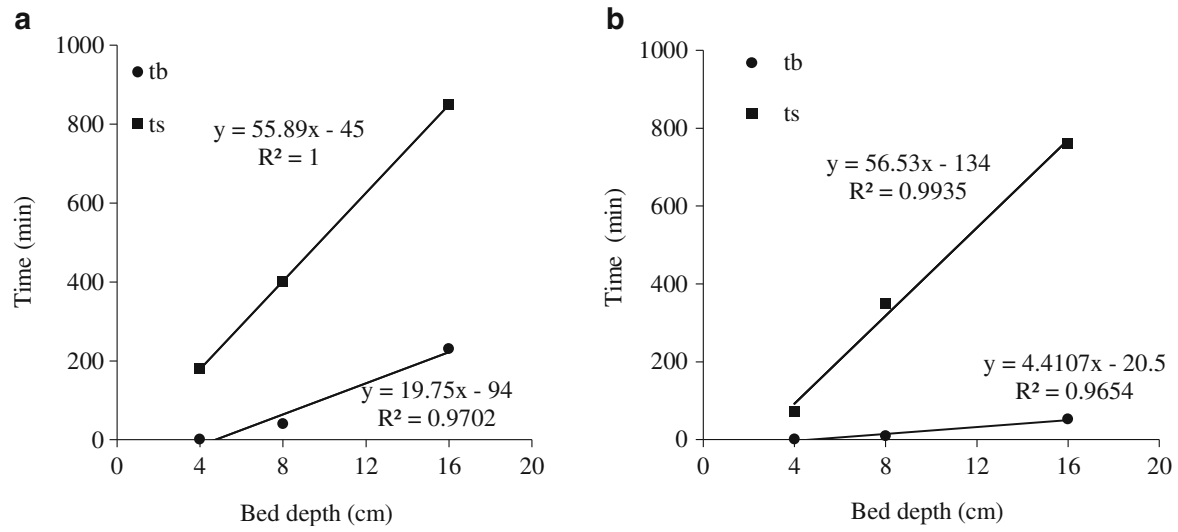

Fig. $3 t_{\mathrm{b}}$ and $t_{\mathrm{s}}$ vs. bed depth for Na-zeolitic tuff and carbonaceous material

\subsection{Thomas Model}

A model for the breakthrough curves obtained for chromatography columns was proposed (Singh et al. 2012). The main advantages of this model are its simplicity and reasonable accuracy in predicting the breakthrough curves under various experimental conditions (Köse and Öztürk 2008).

Thomas model assumes the Langmuir kinetics of adsorption-desorption and no axial dispersion and is derived from the adsorption that the rate driving force obeys second-order reversible reaction kinetics. This model also assumes a constant separation factor, and it is applicable to either favorable or unfavorable isotherms. The primary weakness of Thomas model is that its derivation is based on second-order reaction kinetics. Sorption is usually not limited by chemical reaction kinetics but it is often controlled by interphase mass transfer. This discrepancy can lead to some error when this method is used in adsorption processes (Hasan et al. 2010; Rozada et al. 2007; Ahmad and Hameed 2010).

Figures 1 and 2 show the breakthrough curves fitted to the Thomas model, and the parameters obtained are shown in Tables 4 and 5. According to the figures, it is observed that the saturation time increased as the bed depth increased for both adsorbents. As shown in Tables 4 and 5, the value of the kinetic constant $K_{\text {Th }}$ decreased as the adsorption capacity $\left(q_{\mathrm{o}}\right)$ and bed depth increased. It was found that the regression coefficient $\left(R^{2}\right)$ for both adsorbents was $>0.94$. According to Lodeiro et al. (2006), for the majority of cases, the Thomas and Bohart-Adams models are able to describe rupture curves precisely, and at the same time, kinetic constants $(k)$ can be determined. Hasan et al. (2010) studied the adsorption of $\mathrm{Se}(\mathrm{IV})$ and $\mathrm{Se}(\mathrm{VI})$ by agroindustrial waste and wheat bran; they reported that, when the bed depth increased, the axial dispersion of the mass transfer decreased, and therefore, the diffusion of the adsorbate into the sorbent increased. According to the batch results reported in a previous work (GutiérrezSegura et al. 2012), the kinetic constants and the correlation coefficients of second-order model are higher for the Na-zeolitic tuff than carbonaceous material, and the Langmuir isotherm indicates that the adsorption capacity $\left(q_{\mathrm{e}}\right)$ was higher for Na-zeolitic tuff $(17.63 \mathrm{mg} / \mathrm{g})$ than for carbonaceous material $(15.13 \mathrm{mg} / \mathrm{g})$, and the parameter $b$ for Na-zeolitic tuff and carbonaceous material is of the same order of magnitude, which indicates similar affinities of cadmium for both materials; these results agree to the Thomas model theory. Therefore, it is recommended to use Na-zeolitic tuff rather than carbonaceous material for the removal of cadmium in column systems. The best results were found for the column with the highest bed depth for both adsorbents, and it was found that the adsorption capacities $\left(q_{o}\right)$ of the Na-zeolitic tuff for cadmium at saturation were 2.9, 1.7, and 1.6 times higher than the capacities found for carbonaceous material at bed depth of 4,8 , and $16 \mathrm{~cm}$, respectively.

\subsection{The Yoon-Nelson Model}

The Yoon and Nelson model is not less complicated than other models, and it does not require any detailed data concerning the characteristics of the adsorbate, the type of the adsorbent, or the physical properties of the sorption bed. This model is based on the assumption that the rate of decreasing in the probability of adsorption for each adsorbate molecule is proportional 
to the probability of adsorbate adsorption and the probability of adsorbate breakthrough on the adsorbent (Hasan et al. 2010; Köse and Öztürk 2008).

The adjustment of the experimental results fitted to the Yoon-Nelson model is shown in Figs. 1 and 2, and the parameters $K_{\mathrm{YN}}, \tau$, and $q_{\mathrm{o}}$ obtained are presented in Tables 4 and 5 for both adsorbents. The rate constant $K_{\mathrm{YN}}$ in general decreased, and the $50 \%$ breakthrough time $\tau$ increased with increasing bed depth (Tables 4 and 5). As shown in Figs. 1 and 2, the breakthrough curves shifted gradually to the right and the saturation times (180, 400, and $850 \mathrm{~min}$ for 4, 8, and 16-cm bed depth, respectively) for cadmium increased as the bed depth increased for Na-zeolitic tuff; a similar behavior was observed for carbonaceous material. The increase of contact times when the bed length increases is responsible for this behavior (Ahmad et al. 2006); the fixed-bed column performance depends on the contact time. It is also evident from Tables 4 and 5 that the adsorption capacities calculated by Thomas and YoonNelson models are similar for Na-Z and carbonaceous material. According to the results, the maximum adsorption capacities for both adsorbents increased proportionally with the bed depth of the column.

\subsection{Mass Transfer Model}

The experimental data could be fitted to the Thomas, Bohart-Adams, and Yoon-Nelson models. However, those models are undefined mathematically when the effluent concentration approaches zero during the initial period of the adsorption process. The mass transfer coefficient, $k\left(\mathrm{~min}^{-1}\right)$, is often derived from semiempirical correlations relating the parameters given in Table 6 .

Table 6 Values of the mass transfer model parameters

\begin{tabular}{|c|c|c|}
\hline & Na-zeolitic tuff & Carbonaceous material \\
\hline \multicolumn{3}{|l|}{ Prior parameter } \\
\hline Porosity & 0.47 & 0.64 \\
\hline$K(\mathrm{mg} / \mathrm{L})$ & 9.1 & 10 \\
\hline \multicolumn{3}{|c|}{ Mass transfer model } \\
\hline$K(\mathrm{mg} / \mathrm{L})$ & 9.1 (fixed value) & 10 (fixed value) \\
\hline$D\left(\mathrm{dm}^{2} / \mathrm{min}\right)$ & $5 \times 10^{-6}\left(5 \times 10^{-6}\right)$ & $5.4 \times 10^{-6}\left(5 \times 10^{-6}\right)$ \\
\hline$k\left(\min ^{-1}\right)$ & $0.008(0.0005)$ & $0.01(0.0005)$ \\
\hline$q_{\max }(\mathrm{mg} / \mathrm{g})$ & $18.5(0.1)$ & $12(0.1)$ \\
\hline
\end{tabular}

$(*)=$ Standard deviation
The influences of the following parameters on the model were evaluated for the three heights of bed of zeolitic tuff or carbonaceous material:

- $D$, the diffusion coefficient

- $k$, the mass transfer coefficient

- $K$, the adsorption constant of the Langmuir isotherm equation

- $q_{\max }$ the maximum uptake of substrate adsorbed on adsorbent

Figure $4 \mathrm{a}$, c shows the influence of these parameters upon the shape and position of the breakthrough curves. From these figures, it appears that $K$ and $q_{\max }$ have the highest dependence since both present a symmetric behavior; also, it is observed that $D$ is low sensitive. Therefore, the estimated parameters could not be considered when there is a high dependence between them or if the model is not sensitive to some parameter.

Numerous simulations were performed until the best adjustments were achieved for values of $k, K, D$, and $q_{\max }$, according to experimental data for zeolitic tuff and carbonaceous materials. When $K$ was kept fixed, the other parameters $\left(k, D\right.$, and $\left.q_{\max }\right)$ varied at different values and vice versa (Table 6). For all cases, it was observed that the influence of diffusion coefficient (D) onto process is negligible due to its very low value because its contribution is depreciable compared with the other parameters and therefore, the dispersion was insignificant. Then, this value can be kept in the model or it can be removed because it does not affect the other parameters; similar behaviors were observed for both adsorbent materials. In general, the standard deviations were low and $q_{\text {max }}$ were of same order of magnitude in comparison to equilibrium isotherms.

In the adsorption of complex phenolic compounds on active charcoal, it was found that the parameter that most affects the value of the critical time of breakthrough curves is the mass transfer coefficient $k$. The adsorbent mean particle diameter and the adsorption isotherm pattern are not governing parameters for critical time estimation (Richard et al. 2010).

The cadmium breakthrough curves of zeolitic tuff predicted by the mass transfer model are illustrated in Fig. $4 \mathrm{~b}$, and $K, k, D$, and $q_{\max }$ parameters are reported in Table 6. The experimental data could be well fitted to the mass transfer model for the three 
(a)

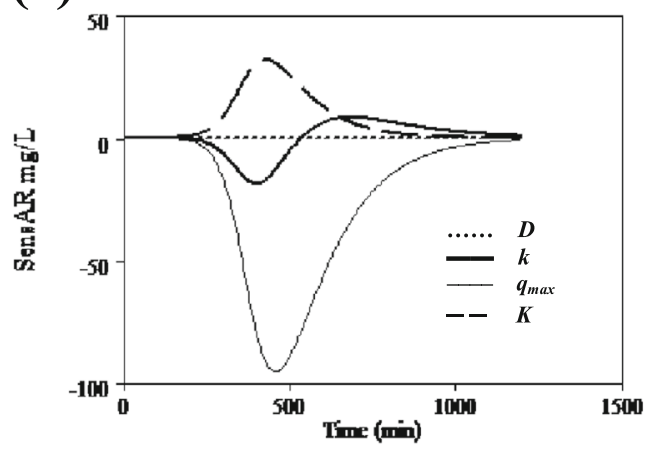

(c)

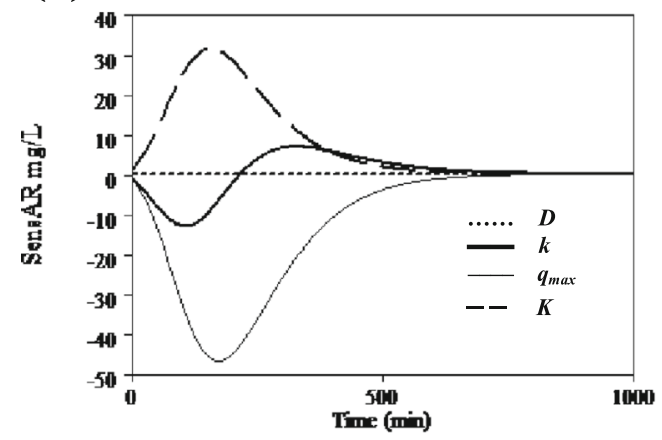

(b)

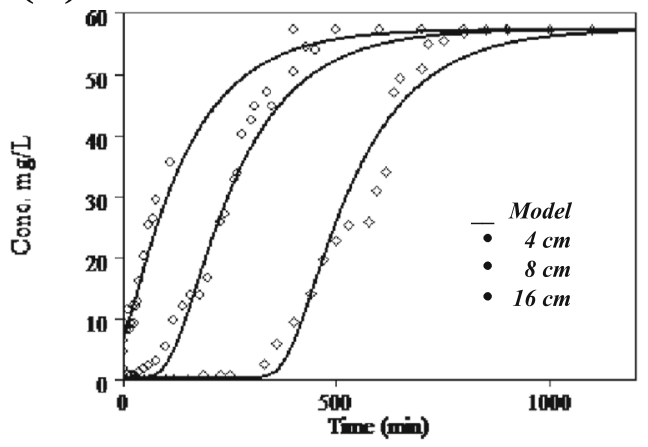

(d)

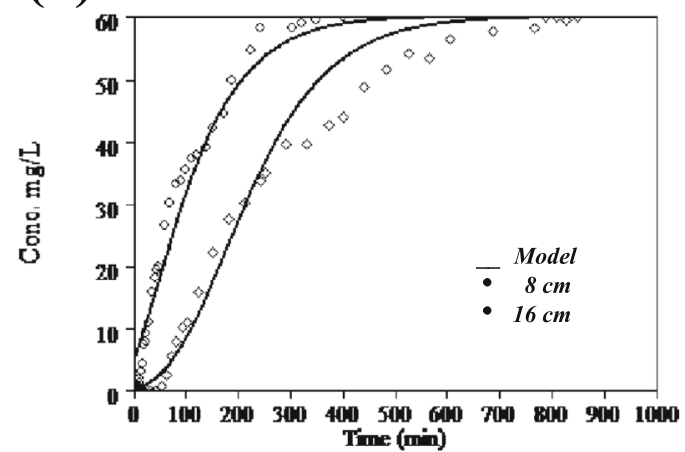

Fig. 4 Sensitivity analyses of concentration with respect to $D, k, q_{\max }$, and $K$ for a zeolitic tuff and c carbonaceous material. Adjustments of the experimental results to the mass transfer model for $\mathbf{b}$ zeolitic tuff and $\mathbf{d}$ carbonaceous material

curves. However, it was necessary to eliminate a section (200-400 $\mathrm{min}$ ) because the results did not correspond to the experimental data. Borba et al. (2008) explained that this behavior is possible due to hydrodynamic deviations such as axial dispersion related with the velocity gradients into the column.

Figure $4 \mathrm{~d}$ shows the adjustments of the experimental results to the mass transfer model for carbonaceous material. It can be seen that the 8 and $16-\mathrm{cm}$ breakthrough curves data could be satisfactorily fitted to the mass transfer model, as supported by the low relative standard deviation between experimental data and model prediction (Table 6) but this was not possible using the data of the column of $4 \mathrm{~cm}$ due to the short longitude because it affects the hydraulic performance of the experiment. Finally, it was decided to use 8 and 16-cm breakthrough curves data where $K$ was fixed as 10 , the estimated value of $D$ was an order lower, and its adjustment was acceptable for 8 and 16-cm breakthrough curves (Fig. 4d).

\section{Conclusions}

The experimental results showed that Na-zeolitic tuff and carbonaceous material are effective adsorbents for the removal of cadmium from aqueous solutions in fixed-bed systems. Increasing the bed depth, the adsorption performance improved. The Bohart, Thomas, and Yoon-Nelson models were successfully used to fit the column data at different depths. AUR was lower for Na-zeolitic tuff than carbonaceous material to treat $1 \mathrm{~L}$ cadmium solution of $60 \mathrm{mg} / \mathrm{L}$.

The experimental data could be fitted to the mass transfer model, and the parameters obtained agree well with known values or exhibit expected trends when absolute values are not known. All of these indicate that diffusion-dispersion is negligible.

The influence of the parameters of model was evaluated and was detected that the parameters $K$ and $q_{\max }$ showed a structural dependence and that $D$ value is depreciable for both adsorbents. The value 
of $q_{\max }$ estimated by mass transfer model was similar to batch studies.

Acknowledgments We acknowledge financial support from CONACYT, project 131174Q, and PROMEP/103.5/13/6535 project.

\section{References}

Ahmad, A. A., \& Hameed, B. H. (2010). Fixed-bed adsorption of reactive azo dye onto granular activated carbon prepared from waste. Journal of Hazardous Materials, 175, 298-303.

Ahmad, A. L., Chong, M. F., \& Bhatia, S. (2006). Prediction of breakthrough curves for adsorption of complex organic solutes present in palm oil mill effluent (POME) on granular activated carbon. Industrial Engineering Chemical Research, 45, 6793-6802.

Ahmaruzzaman, M. (2011). Industrial wastes as low-cost potential adsorbents for the treatment of wastewater laden with heavy metals. Advances in Colloid and Interface Science, 166, 36-59.

Badruddoza, A. Z., Shawon, Z. B., Daniel, T. W., \& Uddin, K. H. (2013). $\mathrm{Fe}_{3} \mathrm{O}_{4} /$ cyclodextrin polymer nanocomposites for selective heavy metals removal from industrial wastewater. Carbohydrate Polymers, 91, 322-332.

Barros, M. A. S. D., Silva, E. A., Arroyo, P. A., Tavares, C. R. G., Schneider, R. M., Suszek, M., \& Sousa-Aguiar, E. F. (2004). Removal of Cr(III) in the fixed bed column and batch reactors using as adsorbent zeolite NaX. Chemical Engineering Science, 59, 5959-5966.

Bhattacharyya, K. G., \& Gupta, S. S. (2008). Adsorption of a few heavy metals on natural and modified kaolinite and montmorillonite: a review. Advances in Colloid and Interface Science, 140, 114-131.

Borba, C. E., da Silva, E. A., Fagundes-Klen, M. R., Kroumov, A. D., \& Guirardello, R. (2008). Prediction of the copper (II) ions dynamic removal from a medium by using mathematical models with analytical solution. Journal of Hazardous Materials, 152, 366-372.

Bulut, Y., \& Tez, Z. (2007). Removal of heavy metals from aqueous solution by sawdust adsorption. Journal of Environmental Sciences, 19, 160-166.

Chen, N., Zhang, Z., Feng, C., Li, M., Chen, R., \& Sugiura, N. (2011). Investigations on the batch and fixed-bed column performance of fluoride adsorption by Kanuma mud. Desalination, 268, 76-82.

Cooney, D. O. (1998). Adsorption design for wastewater treatment. USA: Lewis Publisher.

Cortés-Martínez, R., Solache-Ríos, M., Martínez-Miranda, V., \& Alfaro-Cuevas, R. (2009). Removal of cadmium by natural and surfactant-modified Mexican zeolitic rocks in fixed bed columns. Water, Air, and Soil Pollution, 196, 199-210.

Fonts, I., Gea, G., Azuara, M., Ábrego, J., \& Arauzo, J. (2012). Sewage sludge pyrolysis for liquid production: a review. Renewable and Sustainable Energy Reviews, 16, 2781-2805.
Fu, F., \& Wang, Q. (2011). Removal of heavy metal ions from wastewaters: a review. Journal of Environmental Management, 92, 407-418.

Futalan, C. M., Kan, C.-C., Dalida, M. L. P., Pascua, C., Hsien, K.-J., \& Wan, M.-W. (2011). Nickel removal from aqueous solution in fixed bed using chitosan-coated bentonite. Sustainable Environmental Research, 21, 361-367.

Fytili, D., \& Zabaniotou, A. (2008). Utilization of sewage sludge in EU application of old and new methods - a review. Renewable and Sustainable Energy Reviews, 12, 116-140.

Girgis, M. J., Kuczynski, L. E., Berberena, S. M., Boyd, C. A., Kubinski, P. L., Scherholz, M. L., Drinkwater, D. E., Shen, X., Babiak, S., \& Lefebvre, B. G. (2008). Removal of soluble palladium complexes from reaction mixtures by fixed-bed adsorption. Organic Process Research \& Development, 12, 1209-1217.

Goel, J., Kadirvelu, K., Rajagopal, C., \& Garg, V. K. (2005). Removal of lead(II) by adsorption using treated granular activated carbon: batch and column studies. Journal of Hazardous Materials, B125, 211-220.

Goyal, M., Bhagat, M., \& Dhawan, R. (2009). Removal of mercury from water by fixed bed activated carbon columns. Journal of Hazardous Materials, 171, 1009-1015.

Gutiérrez-Segura, E., Colín-Cruz, A., Fall, C., Solache-Ríos, M., \& Balderas-Hernández, P. (2009). Comparison of Cd-Pb adsorption on commercial activated carbon and carbonaceous material from pyrolyzed sewage sludge in column system. Environmental Technology, 30, 455-461.

Gutiérrez-Segura, E., Solache-Ríos, M., Colín-Cruz, A., \& Fall, C. (2012). Adsorption of cadmium by $\mathrm{Na}$ and Fe modified zeolitic tuffs and carbonaceous material from pyrolyzed sewage sludge. Journal of Environmental Management, 97, 6-13.

Hamidpour, M., Kalbasi, M., Afyuni, M., Shariatmadari, H., Holm, P. E., \& Hansen, H. C. B. (2010). Sorption hysteresis of $\mathrm{Cd}(\mathrm{II})$ and $\mathrm{Pb}$ (II) on natural zeolite and bentonite. Journal of Hazardous Materials, 181, 686-691.

Han, R., Zou, L., Zhao, X., Xu, Y., Xu, F., Li, Y., \& Wang, Y. (2009). Characterization and properties of iron oxide-coated zeolite as adsorbent for removal of copper (II) from solution in fixed bed column. Chemical Engineering Journal, 149, 123-131.

Hasan, S. H., Ranjan, D., \& Talat, M. (2010). Agro-industrial waste 'wheat bran' for the biosorptive remediation of selenium through continuous up-flow fixed-bed column. Journal of Hazardous Materials, 181, 1134-1142.

Hashim, M. A., Mukhopadhyay, S., Sahu, J. N., \& Sengupta, B. (2011). Review: Remediation technologies for heavy metal contaminated groundwater. Journal of Environmental Management, 92, 2355-2388.

Jain, M., Garg, V. K., \& Kadirvelu, K. (2013). Cadmium (II) sorption and desorption in a fixed bed column using sunflower waste carbon calcium-alginate beads. Bioresource Technology, 129, 242-248.

Jamil, T. S., Ibrahim, H. S., Abd El-Maksoud, I. H., \& El-Wakeel, S. T. (2010). Application of zeolite prepared from Egyptian kaolin for removal of heavy metals: I. Optimum conditions. Desalination, 258, 34-40.

Ji, F., Li, C., Tang, B., Xu, J., Lu, G., \& Liu, P. (2012). Preparation of cellulose acetate/zeolite composite fiber and its adsorption behavior for heavy metal ions in aqueous solution. Chemical Engineering Journal, 209, 325-333. 
Köse, T. E., \& Öztürk, N. (2008). Boron removal from aqueous solutions by ion-exchange resin: column sorption-elution studies. Journal of Hazardous Materials, 152, 744-749.

Kumar, U., \& Bandyopadhyay, M. (2006). Fixed bed column dor $\mathrm{Cd}(\mathrm{II})$ removal from wastewater using treated rice husk. Journal of Hazardous Materials, B129, 253-259.

Lesmana, S. O., Febriana, N., Soetaredjo, F. E., Sunarso, J., \& Ismadji, S. (2009). Review. Studies on potential applications of biomass for the separation of heavy metals from water and wastewater. Biochemical Engineering Journal, 44, 19-41.

Lodeiro, P., Herrero, R., \& Sastre de Vicente, M. E. (2006). The use of protonated Sargassum muticumas biosorbent for cadmium removal in a fixed-bed column. Journal of Hazardous Materials, B137, 244-253.

Machida, M., Fotoohi, B., Amamo, Y., Ohba, T., Kanoh, H., \& Mercier, L. (2012). Cadmium(II) adsorption using functional mesoporous silica and activated carbon. Journal of Hazardous Materials, 221-222, 220-227.

Muhamad, H., Doan, H., \& Lohi, A. (2010). Batch and continuous fixed-bed column biosorption of $\mathrm{Cd}^{2+}$ and $\mathrm{Cu}^{2+}$. Chemical Engineering Journal, 158, 369-377.

Naja, G., \& Volesky, B. (2008). Optimization of a biosorption column performance. Environmental Science and Technology, 42, 5622-5629.

NOM-002-SEMARNAT (1996). SEMARNAT, Norma Oficial Mexicana. Diario Oficial de la Federación 23 de abril de 2003.

Pastrana-Martínez, L. M., López-Ramón, M. V., FontechaCámara, M. A., \& Moreno-Castilla, C. (2010). Batch and column adsorption of herbicide fluroxypyr on different types of activated carbons from water with varied degrees of hardness and alkalinity. Water Research, 44, 879-885.

Pokorna, E., Postelmans, N., Jenicek, P., Schreurs, S., Carleer, R., \& Yperman, J. (2009). Study of bio-oils and solids from flash pyrolysis of sewage sludges. Fuel, 88, 1344-1350.

Richard, D., Delgado-Núñez, M. L., \& Schweich, D. (2010). Adsorption of complex phenolic compounds on active charcoal: breakthrough curves. Chemical Engineering Journal, 158, 213-219.

Rozada, F., Otero, M., García, A. I., \& Morán, A. (2007). Application in fixed-bed systems of adsorbents obtained from sewage sludge and discarded tires. Dyes and Pigments, 72, 47-56.
Saraswat, S., \& Rai, J. P. N. (2010). Heavy metal adsorption from aqueous solution using Eichhornia crassipes dead biomass. International Journal of Mineral Processing, 94, 203-206.

Singh, A., Kumar, D., \& Gaur, J. P. (2012). Continuous metal removal from solution and industrial effluents using Spirogyra biomass-packed column reactor. Water Research, 46, 779-788.

Smith, K. M., Fowler, G. D., Pullket, S., \& Graham, N. J. D. (2009). Sewage sludge-based adsorbents: a review of their production, properties and use in water treatment applications. Water Research, 43, 2569-2594.

Tchobanoglous, G., Burton, F. L., \& Stensel, H. D. (2003). Wastewater engineering: treatment and reuse. New York: McGraw-Hill.

Teutli-Sequeira, A., Solache-Ríos, M., \& Olguín, M. T. (2009). Influence of $\mathrm{Na}^{+}, \mathrm{Ca}^{2+}, \mathrm{Mg}^{2+}$ and $\mathrm{NH}^{4+}$ on the sorption behavior of $\mathrm{Cd}^{2+}$ from aqueous solutions by a Mexican zeolitic material. Hydrometallurgy, 97, 46-52.

Tian, Y., Gao, B., Morales, V. L., Chen, H., Wang, Y., \& Li, H. (2013). Removal of sulfamethoxazole and sulfapyridine by carbon nanotubes in fixed-bed columns. Chemosphere, 90, 2597-2605.

Torres Pérez, J., Solache-Ríos, M., \& Colín Cruz, A. (2008). Sorption and desorption of dye remazol yellow onto a Mexican surfactant-modified clinoptilolite-rich tuff and a carbonaceous material from pyrolysis of sewage sludge. Water, Air, \& Soil Pollution, 187, 303-313.

Wang, L.-H., \& Lin, C.-I. (2010). The removal of heavy metal ions from spiked aqueous solutions using solid wastes - comparison of sorption capability. Journal of the Taiwan Institute of Chemical Engineers, 41, 585-590.

Won, W., Lee, S., \& Lee, K. S. (2012). Modeling and parameter estimation for a fixed-bed adsorption process for $\mathrm{CO} 2$ capture using zeolite 13X. Separation and Purification Technology, 85, 120-129.

World Health Organization. (2008). Guidelines for drinking-water quality (3rd ed.). Geneva: World Health Organization. 317.

Zulfadhly, Z., Mashitah, M. D., \& Bhatia, S. (2001). Heavy metals removal in fixed-bed column by the macro fungus Pycnoporus sanguineus. Environmental Pollution, 112, 463-470. 